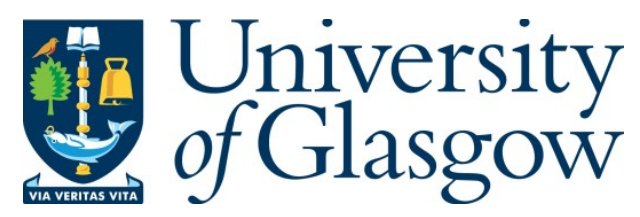

Prina, F. (2020) The mechanics of consensus: non-territorial national cultural autonomy and the Russian state. Nationalities Papers, 48(2), pp. 307-322.

(doi: $\underline{10.1017 / n p s .2018 .39)}$

This is the Author Accepted Manuscript.

There may be differences between this version and the published version. You are advised to consult the publisher's version if you wish to cite from it.

https://eprints.gla.ac.uk/164961/

Deposited on: 5 July 2018

Enlighten - Research publications by members of the University of Glasgow http://eprints.gla.ac.uk 


\title{
The Mechanics of Consensus: Non-Territorial National Cultural Autonomy and the Russian State
}

\begin{abstract}
Russia's institutions on non-territorial cultural autonomy (NTCA) can be broadly situated within the country's "political community," in the sense that they - for the most part recognize the government's rules of engagement and its role as decision-maker, leading to an overarching consensus and pursuit of shared objectives. At the same time, they remain at the periphery of the political community. This article outlines the reasons for NTCA institutions' peripherality and limited influence upon Russia's minority policies. Such reasons are linked to external factors (Russia's undemocratic political system), but also to conditions intrinsic to NTCA institutions themselves (forms of "passivity" and (non-)participation, and blurred boundaries between NTCA institutions and state actors). The interaction of such factors generates the noted prevailing consensus between NTCA institutions and the Russian state. Interview data further reveal that representatives of NTCA institutions are far from monolithic: the said external and internal factors affect them in different ways, resulting in variations in forms of consensus and cooperation with state actors. This, in turn, allows for multiple interpretative frameworks of state-civil society coexistence in the sphere of Russia's diversity management.
\end{abstract}

Keywords: Russian Federation; national cultural autonomy; political community; civil society; participation; self-governance

This article analyzes the positioning, within Russia's socio-political order, of institutions for the representation of ethnic minority interests based on non-territorial cultural autonomy (NTCA): national cultural autonomies and peoples' congresses. ${ }^{1}$ NTCA institutions can be broadly situated within the country's "political community," 2 in the sense that they - for the

\footnotetext{
1 The research for this article was carried out under the project "National Minority Rights and Democratic Political Community: Practices of Non-Territorial Autonomy in Contemporary Central and Eastern Europe" (2014-2017). The research was supported by the Economic and Social Research Council [grant number ES/L007126/1]. The data will be deposited with the UK Data Service Data, Collection Number 852375.

${ }^{2}$ I use Juviler and Stroschein's definition, as:
}

$[\ldots]$ the collection of persons in and out of government who recognize the government as the legitimate decision maker for that territory, generally comply with its decisions, and cooperate_toward shared purposes. (Juviler and Stroschein 1999, 438) 
most part - recognize the government's rules of engagement and its role as decision-maker, leading to an overarching consensus and pursuit of shared objectives. At the same time, they remain at the periphery of Russia's political community, with scarce influence on decisionmaking or on society more broadly - resulting in feeble voices in the articulation of minority concerns. On the basis of qualitative data from interviews in Russia, this article outlines the reasons for NTCA institutions' peripherality and limited impact upon Russia's minority policies. Such reasons are linked to “obvious" external factors (Russia's undemocratic political system), but also to conditions intrinsic to NTCA institutions themselves (forms of "passivity" and (non-)participation, blurred boundaries between NTCA institutions and state actors). The interaction of such - external and internal - factors generates the noted prevailing consensus between NTCA institutions and the Russian state. Interview data further reveal that representatives of NTCA institutions are far from monolithic: external and internal factors affect them in different ways, resulting in variations in forms of consensus and cooperation with state actors. This, in turn, allows for multiple interpretative frameworks of state-civil society coexistence in the sphere of Russia's diversity management. This article can be located within the broader research on civil society-state relations in authoritarian contexts (Hilliker 2012; Horvath 2011; Korosteleva 2012; Jamal 2007; Lewis 2013; Spires 2011; Ziegler 2010; Bindman 2015; Cheskin and March 2015), looking at cases of (quasi)civil society ${ }^{3}$ through the prism of diversity management.

Semi-structured, in-depth interviews were carried out between June 2015 and June 2016 in six cities of the Russian Federation: in four ethnic republics - Saransk (Republic of Mordovia), Petrozavodsk (Karelia), Kazan (Tatarstan) and Ufa (Bashkortostan) - as well as in Moscow and St. Petersburg. In total 76 persons were interviewed, from civil society (national cultural autonomies, peoples' congresses and minority NGOs), as well as academics and public officials. ${ }^{4} \mathrm{I}$ refrain from indicating the exact number of respondents who expressed particular views: given the relatively small sample of respondents this could be misleading. Rather, I offer my interpretation of the body of data taken as a whole; I only give a general indication as to whether particular views were common or rare to guide the reader this should however be treated with caution, and not seen as a claim of representativeness of specific groups of respondents.

\section{Non-Territorial Cultural Autonomy: International and Russian Conceptions}

NTCA is generally understood as a system that provides for the ethno-cultural accommodation of minorities without carving out autonomous regions within a state. Hence, it is of particular relevance to minorities that are territorially dispersed. The idea of "national cultural autonomy" first appeared at the end of the $19^{\text {th }}$ century, and was promoted by the Austro-Marxists Karl Renner ([1899] 2005) and Otto Bauer ([1907] 2000) as a mechanism to

\footnotetext{
${ }^{3}$ It can be contested that NCTA institutions in Russia should not be classified as "civil society" given their close links with Russian government structures. However, I adopt a broad interpretation of "civil society," to include institutions that are not fully autonomous or separate from the state, and whose role in democratization is not assumed (see Cheskin and March 2015, 264). This is discussed below.

${ }^{4}$ In this article I mostly refer to respondents from NTCA institutions, unless otherwise indicated. The respondents were of a range of ethnic backgrounds: approximately one third were Tatars, while others were of Finno-Ugric (including Mordovian), Jewish, Ukrainian, German ethnicity, in addition to some respondents originating from Central Asian countries. Ten respondents did not belong to an ethnic minority.
} 
address various groups' ethno-cultural and linguistic needs while maintaining intact the Austro-Hungarian Empire as a polity. It is based on the "personality principle": the notion that minority groups can be autonomous within a multi-ethnic state, regardless of place of residence. The proposed model envisaged self-government in the spheres of culture and education, with minority-language or bilingual institutions at the local level.

The notion of NCTA has recently raised the interest of academics (Malloy, Osipov, and Vizi 2015; Nimni 1999, 2005, 2007; Nimni, Osipov, and Smith 2013; Roach 2005; Smith and Cordell 2008), and some of its features have been incorporated into the law and practice of a number of countries, including post-Communist ones. ${ }^{5}$ Multiple forms of NTCA have been developed in a range of historical and political contexts (Malloy, Osipov, and Vizi 2015). While the exact scope of NCTA remains somewhat undefined, autonomy implies communities being in a position to regulate matters relating to their cultures and languages. Despite this basic understanding of NCTA as self-governance, for the purposes of this article I place cultural autonomy in the wider context of participation. The OSCE Lund Recommendations on the Effective Participation of National Minorities in Public Life 6 (hereinafter "the Lund Recommendations") divide participation into "participation in decision-making" (arrangements at central, regional and local government, and elections), and "self-government" (encompassing non-territorial and territorial arrangements). Consequently, cultural autonomy (as self-governance) can be situated within the framework of (broadly-defined) participation. Indeed, successful forms of NTCA have been linked to participation in the life of the state, with relevant competences devolved to minority communities through a diffusion of powers.

This approach reflects a growing consensus on the vital importance of minority participation as a vehicle to societal integration and more stable inter-group relations (Hofmann 2006; Weller and Nobbs 2010). International standards and commentators point to a form of participation that is effective, in the sense that minorities not only have a voice, but their voice is "taken seriously," enabling influence upon decision-making (Marko 2006: 3-4), particularly on matters affecting them. ${ }^{7}$ The analysis of contemporary cases has shown that strong forms of NTCA, enjoying effective participation, are characterized by various factors of which a fundamental one is their development in a democratic environment (Kössler 2015). In line with this, Malloy classifies NCTA on the basis of levels of participation, from that of "voice" (self-governing institutions and effective participation) "quasi-voice" (partial self-governance) and "non-voice" (lack of autonomy and "symbolic policies") (Malloy 2015, 3-4). Similarly, the Lund Recommendations refer to guarantees for minorities to have an "effective voice" at the level of the central government (Recommendation 6). ${ }^{8}$ The reason for

\footnotetext{
${ }^{5}$ Other countries besides Russia are Estonia, Hungary and Serbia.

${ }^{6}$ OSCE High Commissioner on National Minorities, September 1999

${ }^{7}$ See, in particular, the Lund Recommendations and Article 15 of the Framework Convention for the Protection of National Minorities; the latter states that "the Parties shall create the conditions necessary for the effective participation of persons belonging to national minorities in cultural, social and economic life and in public affairs, in particular those affecting them." [italics added].

${ }^{8}$ See also Recommendations 12 and 13, and the Explanatory Note. Similarly, the original (Austro-Marxists') NCTA model already recognised the importance of both national communities' autonomy (in managing cultural
} 
the emphasis on "voice" is the pre-emption of political - as well as cultural - marginalization. Of particular significance are degrees of inclusiveness in the development (and periodic review) of institutional designs upon which the interaction of state organs and minority organisations hinge. ${ }^{9}$

Thus, we treat NTCA as a framework comprising minority self-governance and "voice" through non-territorial arrangements, analysing Russia's forms of NCTA as mechanisms directed at minority accommodation through the realisation of the said framework. There is another reason why NCTA institutions in Russia deserve scholarly attention specifically from the perspective of participation. While the introduction of NCTA institutions in Russia was not motivated on the basis of compliance with international standards (nor did it aim to reproduce the Austro-Marxists' model), the Russian government has linked NCTA to participatory processes, including by referring to the sharing of competences with state structure. It has done so, inter alia, in its reports to the Council of Europe's Advisory Committee on the Framework Convention for the Protection of National Minorities, which enumerate measures towards the treaty's implementation. The Russian authorities further identified a special role for NCTA institutions - within the wider network of minority-related organisations - in the realisation of Russia's minority policies, including through cooperation with state organs within the education system and towards legal reform. ${ }^{10}$ Hence, NCTA institutions should (also) be examined in the context of international instruments to which Russia has acceded - particularly through membership of the Council of Europe and OSCE and of participation-related principles stemming from them.

Russia's NCTA system consists of a vertically integrated system of organizations established at the local, regional and federal levels. National Cultural Autonomies (NCAs) have been established following the adoption of the Federal Law on National Cultural Autonomy (NCA Law) in 1996. ${ }^{11}$ The Law can be seen as an attempt to accommodate Russia's ethnic diversity while assuaging age-old fears of instability and state fragmentation, heightened by the country's territorial vastness and ethno-linguistic diversity. Since 1996 the NCTA system has been widely endorsed by the numerous organizations that have chosen to register as NCAs.

Russia's NTCA framework also comprises "peoples' congresses," another representative institution that operates alongside (and at times jointly with) NCAs. Peoples' congresses are

matters) and mechanisms to share power with state structures (in fulfilling politico-administrative functions) (Renner, 2005, 42).

${ }^{9}$ The Lund Recommendations state: "When creating institutions and procedures in accordance with these Recommendations, both substance and process are important. Governmental authorities and minorities should pursue an inclusive, transparent, and accountable process of consultation in order to maintain a climate of confidence" (Recommendation 5). See also Recommendation 22 on periodic review.

10 See the reports submitted by Russia to the Advisory Committee on the Framework Convention for the Protection of National Minorities (ACFC) (ACFC 2000, pp. 16, 24-25, 39; ACFC 2005, pp. 20, 28, ACFC 2010, pp. 27-28, 46; ACFC 2016; §1.21). See also, for example, Resolution of the Government of the Russian Federation of 29 December 2016 No. 1532 'On the Approval of the State Programme of the RF "Realisation of the State National Policy"; among the stated goals is the "increase of the effectiveness of the cooperation between state organs and NCAs and other institutions of civil society". This active role of NCTA institutions, however, was not found by the ACFC to have been realised (ACFC 2011, §71-75).

${ }^{11}$ Law "On National Cultural Autonomy," No. 74-FZ, 17 June 1996. The text of the law (in Russian) and amendments are available at http://base.garant.ru/135765/. On the Law's adoption, see Osipov (2004) 
ethnicity-based representative assemblies which predate NCAs, having first developed in the early $20^{\text {th }}$ century (Osipov 2011). The main difference between the two institutions is that NCAs are registered according to the NCA Law and, by the same law, they must operate outside a particular group's ethnic republic (if it exists); ${ }^{12}$ by contrast, peoples' congresses are registered as "ordinary" public organizations ${ }^{13}$ and can operate both inside and outside the relevant ethnicity-based territorial formations. Like NCAs, peoples' congresses have a pyramidal structure comprising organisations at the local, regional, and federal levels; unlike NCAs, they also operate at the international level through links with co-ethnics outside Russia. ${ }^{14}$ I use "NCTA" as an umbrella term to designate both NCAs and peoples' congresses.

The NCA Law stresses NCAs' functions of "independently regulating the issues of their [communities'] identity preservation and their linguistic, educational and national cultural development" (Article 1). This is the role of "cultural autonomy" as self-governance, rather than participation in decision-making more broadly. ${ }^{15}$ Yet, as noted, I treat the two forms of participation as interlocking. With reference to decision-making Russia's NCTA institutions remain at the margins of political processes, by which they are called upon to comply with existing rules of engagement, but not to be active members in the shaping of such rules (Prina, forthcoming). Meanwhile, Russian NCAs are closer to NGOs than to bodies vested with public functions so as to exercise minority self-governance and articulate minority voices. The NCA Law's provisions are often declarative and devoid of detailed responsibilities of government organs. Consequently, NCAs have been criticized as ineffective (Bowring 2005, 2007) and described as "a deteriorated version" of NGOs (Osipov 2011, 3). ${ }^{16}$ Restricted (ineffective) participation likely impairs the NCTA institutions' selfgoverning functions (by confining engagement in cultural matters to that of "regular" civil society organisations), while the declarative nature of the NCA Law's provisions results in the limited institutionalization of NCTA organisations within in the Russian system of diversity management.

In this article I do not ask whether, in light of the shortcomings mentioned above, Russia's NCAs and peoples' congresses should be analyzed as NTCA institutions, or whether they should be located outside this framework. Rather, I examine the institutions as they are, unpacking the reasons why they function in a particular manner and how minority representatives navigate them, taking into account variance among the respondents. Moreover, while interviews were also conducted with non-NCTA organizations - to gain a deeper understanding of the environment in which minority organizations as a whole operate

\footnotetext{
${ }^{12}$ Despite this general rule, the federal Tatar NCA has its headquarters in Kazan, Tatarstan.

13 See Article 21, Federal Law “On Public Organizations,” No. 82-FZ, 19 May 1995.

${ }^{14}$ Peoples' congresses in the regions visited during the fieldwork were: the World Congress of Tatars, the InterRegional Public Organization of Mordovian (Moksha and Erzya) Peoples, the Congress of Karelians, and the World Kurultaj (Congress) of Bashkirs.

${ }^{15}$ Consultative functions are also foreseen by the NCA Law (Art. 7) although, less prominently than NCAs' self-governning role.

${ }^{16}$ Given that restrictions apply to their activities compared to 'regular' NGOs (Osipov 2015a, 185-86).
} 
- I focus on NCTA institutions given the special role attributed to them by the Russian government.

\section{NTCA and the Russian State: Consensus and its Dynamics}

Interview data point to a prevailing consensus between NTCA institutions and government organs. The majority of NTCA respondents expressed satisfaction with the existing institutional design in the sphere of diversity management, while laws and policies did not raise major concerns. Respondents tended to subscribe to the view that government officials strove to accommodate them where possible - for example by providing venues for events and exhibitions upon request - and that programmes promoting minority cultures and languages were circumscribed by limited resources rather than by a lack of willingness to engage in, or support, such activities. When NTCA respondents were asked about potential difficulties they encountered, they - for the most part - pointed out that obstacles they may face, such as scarce funding, were common to all organizations and cut across ethnic groups. ${ }^{17}$ Some stressed that problems arising from financial constraints transcended Russia's borders, given the linkages between Russian and international markets. It was not infrequent for questions on possible difficulties affecting NTCA institutions to lead to an uncomfortable atmosphere and to a somehow defensive attitude, with the respondents emphasizing that ethnicity-based organizations had no disadvantages compared to other public organizations.

Certainly in some instances these "positive" attitudes might have been exaggerated, or faked, with respondents refraining from criticism of the authorities for fear of possible consequences, particularly given that interviews were conducted by foreign researchers. At the same time, Russian scholar Alexander Osipov (2015a) has similarly recorded a generalized tendency for minority groups to regard the NTCA system as legitimate. In light of the common acceptance of existing practices, NTCA institutions can be located within Russia's "political community."18

The cooperation (and consensus) between NTCA institutions and the Russian authorities result in a political environment where these organizations do not act as a counterweight to the Russian government. They rather "consent" to their peripherality, by adjusting to it. This condition implies a departure from the "heroic narrative of civil society" (Lewis 2013, 327), which has treated NGOs as drivers of democratization (see also Cheskin and March 2015). In conceptualizing civil society's positionality in authoritarian states, Lewis (2013) identifies a cluster of interpretations to account for cases in which civil society succeeds in coexisting with the state. Explanations include a common political culture shared by state and non-state actors, and a complementarity of functions, ${ }^{19}$ engendering a mutually beneficial relationship (functionalist approach). An alternative reasoning focuses on civil society being tolerated by the state but being effectively excluded from the public sphere. This scenario is drawn from Young $(2000,163-80)$ and the dual approach to civil society as "self-organization" and as

\footnotetext{
17 There were some exceptions, outlined below.

${ }^{18}$ See footnote 2 on the definition.

${ }^{19}$ On state-civil society interdependence in Russia, and relevant Soviet legacies, see Ljubownikow, Crotty and Rodgers (2013).
} 
"public sphere," 20 the former relates to an association's expression of group consciousness and services provided to the group, ${ }^{21}$ and the latter to the input of civil society into the public sphere. ${ }^{22}$ Lewis (2013) argues that, in many authoritarian states, civil society is allowed to operate in the mode of "self-organization," but is prevented from articulating non-official discourses (this approach can be referred to as the discursive interpretative framework). While the political culture and functionalist approaches enable us to understand situations in which civil society and the state cooperate (particularly in cases of mutual dependency), Lewis sees the third interpretative framework as shedding light on instances in which contestation is present, along with high, or relatively high, levels of state coercion.

The analysis of NTCA in Russia has to be approached from the point of view of multiple forms of consensus: taking account of this variance, all three frameworks outlined above coexist in Russian society. The discursive framework applies in all cases, as will be shown below, while the political culture and functionalist approaches apply in numerous, but not all, cases. In this sense, while dominant narratives on inter-ethnic relations are resilient, alternative interpretations of social reality also exist, although the practical means to transform them into widespread social phenomena continue to be absent.

\section{NTCA's Peripherality and Consensus}

It has already been noted that, while NTCA respondents were largely confined to the margins of Russia's political community, in interviews they mostly recognized the government's rules of engagement and role as decision-maker. At the same time, the opinions expressed, while often positive vis-à-vis the state, were not uniform: many respondents were (at least outwardly) fully pro-government, some were in disagreement with government policies, and the remaining respondents could be located somewhere between these two poles. The respondents engaged in various forms of cooperation with government structures in the presence of varying levels of agreement (or disagreement) with official positions.

I leave aside considerations as to whether a "consensus" between two sides with a highly skewed power imbalance - in a situation of political centralism, with the state dictating the terms of the "consensus" - leads to instability in the long term (or whether this can be called "consensus" at all). I focus on the fact that existing practices and rules of engagement appear to have generally been accepted by the stakeholders, despite the fact that the influence ("voice") of NTCA institutions remains feeble. The few respondents from NTCA institutions who expressed critical or partially critical opinions, as well as observers located outside of the NTCA system, elucidated some of the reasons for the widespread acceptance of ongoing practices.

\section{The External Environment: Russia's Political Centralism}

The inflexibility of Russia's political system is undoubtedly a highly significant factor in reducing the influence of civil society's (including NTCA institutions') voices, along with the

\footnotetext{
${ }^{20}$ Itself drawn from Cohen and Arato's (1994) dualistic approach to civil society as "defensive" and "offensive" (Young 2000, 163).

21 “[T]he way associations [...] develop forms of communicative interaction that support identities, expand participatory possibilities, and create networks of solidarity" (Young 2000, 163).

${ }^{22}$ Associational activity "that aims to influence or reform state or corporate policies and practices" (ibid).
} 
impenetrability of what is known as Putin's "power vertical." The tight networks of the "vertical" complicate the process of locating points of pressure within the system that may yield to intervention by civil society actors. Russia has been classified as a "hybrid" regime: a system with authoritarian traits (Ambrosio [2009] 2016), which nevertheless legitimizes itself through a veneer of democratic processes (Shevtsova 2001; Wilson 2005). Meanwhile, under Putin the idea of Russia's exceptionalism vis-à-vis the international community has been heavily promoted, including by embracing the authoritarian-liberal hybrid model of "sovereign democracy" in the second half of the 2000s (Okara 2007).

In this type of (semi-)authoritarian regime loyalty and mass support are of vital importance (Gel'man and Starodubtsev 2016, 102). In order to contain dissent, the political system needs to "absorb" civil society, while also presenting a semblance of invincibility (Gel'man and Starodubtsev 2016) which can discourage calls for the subversion of the existing political order. One of the means to this end is the vetting of civil society organizations, resulting in either their "licensing" or repression (Robertson 2009). Even when endorsement is granted, it can be arbitrarily withdrawn, thus encouraging only acceptable forms of civic activism and political participation (Robertson 2009, 541, 545). Civil society can be easily discredited through the labelling of its organizations as "foreign agents," ${ }^{23}$ while the Putin leadership has introduced an array of legal and policy changes that have severely reduced civil society's ability to function in Russia (Gilbert 2016; Lavinski 2013; Horvath 2011). In this context, a respondent observed that (potential) beneficiaries of the NTCA system feared possible risks of "contradicting" the state authorities when engaging in activities for the promotion of minority cultures and languages:

A proportion of citizens are afraid. For example, when I go to some provincial city, I am asked: "Are you allowed to do this? Does the $\mathrm{FSB}^{24}$ or government allow you to do this?" I reply that I am just doing it, not asking for permission. However, some people, especially older ones, have this fear in their blood..$^{25}$

Some respondents believed that minority issue remained a low priority in government programmes, thereby reinforcing NTCA's peripherality, while also being situated in a securitized context. The securitization of domestic policies can trigger minority groups' concern that they may be labelled as "extremists" if they do not demonstrate sufficient loyalty to the Russian state. ${ }^{26}$ If political centralization is added to the legal and administrative complexity of a geographically vast country such as Russia, it becomes apparent how

\footnotetext{
${ }^{23}$ See below (Disempowered NTCA Institutions).

${ }^{24}$ Russian security services.

${ }^{25}$ Interview with the director of a federal NCA, Moscow, 27 May 2016.

${ }^{26}$ Interviews with the representatives of an NGO providing legal aid to migrants, and with the representative of an association uniting people from the Caucasus, Moscow, 30 May 2016. The complex issue of securitization of domestic politics under Putin cannot be included in this article due to space restrictions. For an overview, see Bacon and Renz (2006).
} 
deviating from ongoing practices, and engendering any type of reform, is arduous if not beyond the bounds of possibility. ${ }^{27}$

\section{Disempowered NTCA Institutions}

Russia's political environment has produced, unsurprisingly, a weak and inflexible NTCA system. According to a respondent who was critical of the system, the purpose of the NCA Law was to give a mere illusion of accommodation of minority concerns, as its provisions are devoid of a mechanism of implementation. ${ }^{28} \mathrm{He}$ argued that:

Although these [NCTA] institutions have a certain unifying role, they do not have opportunities to preserve [a minority] language. They do not have instruments. They [NTCA representatives] can gather, talk and leave. For example, in Tatarstan people are united under the umbrella of the World Congress of Tatars. Of course, you can raise a question [on the occasion of a meeting of the Congress], a record of it will be made. However, their resolutions [adopted by the Congress] are the same from year to year [...]. You will not be able to find a line about the realization of these resolutions. [...] They cannot realize them, because they do not have instruments to do so. They do not have structures, bodies, mechanisms of influence. ${ }^{29}$

The respondents referred to two ways in which the absence of "instruments" to operate effectively manifests itself: in a lack of institutionalized channels involving mechanisms to influence minority-related matters (as per the citation above); and in a scarcity of resources, which affects NTCA institutions' capacity. The first case was raised by a small number of respondents, who referred to a façade of participation. For example, a respondent had been invited to take part in public discussions in the Duma on legislative initiatives in the sphere of inter-ethnic relations, which he described as follows:

The decision is already made. The rest is just imitation [of dialogue]. It looks like this: [...]. First, MPs speak, and then they give the floor for five minutes to some representatives of NGOs. Five minutes for all those invited. Of course, people get angry, since they do not understand why they were invited only for five minutes. Then they say "OK, 7 minutes." [On one occasion] we delegated a very active [spokesperson], he started accusing them [public officials] furiously. After this incident, they did not invite any of those present during this hearing. [....$^{30}$

Secondly, respondents referred to limited financial resources. ${ }^{31}$ NCAs (like NGOs) can participate in competitions for grants from the state but they cannot count on a regular inflow of funds. In many cases, the respondents noted that, while more funding would certainly have

\footnotetext{
${ }^{27}$ Indeed, Gel'man and Starodubtsev (2016) argue that policy reform occurs only in the presence of specific conditions: when it constitutes a priority for the regime, when several reformers back it, and when it is adopted speedily, capitalizing on a short-lived momentum.

${ }^{28}$ Interview with a (ethnic Tatar) academic and former public official in Tatarstan. Kazan, 19 May 2016.

${ }^{29}$ Ibid.

${ }^{30}$ Interview with the representatives of an association uniting people from the Caucasus, 30 May 2016. Similarly, the Council of Europe's ACFC has argued that that advisory councils "are expected to implement rather than contribute to the preparation of minority-relevant legislation" (ACFC 2006: §90).

${ }^{31}$ Interview with the representatives of an association uniting people from the Caucasus, 30 May 2016.
} 
been welcome, they were appreciative of what was made available to them. Others were more critical: a respondent (from a federal NCA) argued that irregularity of financing, and inconsistences across regions, ${ }^{32}$ caused NCA activity to be similarly unsystematic and erratic. ${ }^{33}$ One may add that the requirement for organizations to apply for grants for individual projects eases the vetting (followed by the "licensing" or repression) of civil society, while the 2012 "Foreign Agents" Law ${ }^{34}$ restricts funding from abroad. ${ }^{35}$

Besides the scarcity of financial and political capital, the situation of Russian NTCA institutions is well-captured by the discursive interpretative framework described above. NTCA institutions' activity centres around internal management and cultural programmes, which do not influence Russia's political processes (and are thereby "non-discursive," as the institutions are precluded from articulating non-official discourses). They are expected to refrain from political activity, interpreted very broadly: as per the "Foreign Agents" Law, "political activity" encompasses acts "with the objective of impacting on decision-making by the state organs, with a view to changing their policies, and also [...] the formation of public opinion $[\ldots] ., 36$

\section{Internal Factors: Civil Society and "Participation"}

The foregoing shows that part of the reason for the acquiescence to unwritten rules of statecivil society interaction is to be found in the controls placed upon civil society by the Russian government. At the same time, other factors are also at play: forms of "passivity" in civil society activism; blurred boundaries between the state and NTCA institutions; and illusory forms of participation.

\section{Passivity in Activism}

Some respondents - insiders to the NTCA system and also observers - pointed to a generalized passivity in many of their colleagues. A respondent argued that, when he joined his national movement during perestroika, there were "people who wanted to solve problems, and those who wanted the state to solve their problems." 37 He believed that "the Soviet system created apathy in civil society," 38 and that, consequently, in post-Soviet Russia infringements upon citizens' rights were not followed by public outcries: "although civil

\footnotetext{
${ }^{32}$ Grants are administered at the local or regional levels.

${ }^{33}$ Interview with the director of a federal NCA, Moscow, 27 May 2016.

${ }^{34}$ The full name is Federal Law "On the Amendment of Certain Legislative Acts of the Russian Federation in the Regulation of Activities of Non-Commercial Organizations Fulfilling the Functions of Foreign Agents," No. 121-FZ, 20 June 2012. Pursuant to this law, any organization that receives foreign funding and engages in "political activity" must register as an "organization performing the functions of a foreign agent". "Foreign agents' are required to fulfil onerous obligations in reporting their activities and foreign funds. Even before the adoption of the "Foreign Agents" Law, legal restrictions were placed on financing from foreign sources (see Crotty, Hall, and Ljubownikow 2014).

35 Additional - but also generally limited - funding derives from donations from co-ethnics (wealthy businesspeople or community members who pay membership fees or contributions on the occasion of festivals).

${ }^{36}$ Article 2(2), "Foreign Agents" Law.

${ }^{37}$ Interview with the director of a federal NCA, Moscow, 27 May 2016.

${ }^{38}$ Ibid.
} 
society made a huge step forward, it is in its early development stage. Well, let's say it has a big development potential." 39

The expression "passivity" is employed here in the sense of acceptance (or acquiescence) of existing practices and modi operandi. This does not preclude that some NTCA institutions may have very actively engaged in projects and events. When referring to their work towards the preservation of minority cultures and language, NTCA respondents tended to situate it within the existing institutional and legal framework: they did not suggest possible alterations to the NTCA system, or that additional competences be transferred to them - for example, to have more control, or direct management, of minority-language schools. ${ }^{40}$ It was rare for interviewees to argue that NTCA organizations ought to be involved in policy-making: some believed that this was the role of experts and politicians, rather than of public organizations. ${ }^{41}$

Respondents critical of the NTCA system linked this form of passivity to a lack of "democratic experience" in Russia ${ }^{42}$ and to "state/civic institutions" 43 - such as the Presidential Council on Interethnic Relations, the Presidential Council for Civil Society and Human Rights, and Public Chambers, ${ }^{44}$ as well as others with competences in the sphere of inter-ethnic relations: ${ }^{45}$

All these institutions are established from above. Each state body has such an institution [...].. Of course, there are people in these organizations who are actually doing something, they are proposing something. However, in the majority [of cases], people are just spending their time there, either they have their own interests to be there, or they represent somebody's interests, etc. They don't represent society. ${ }^{46}$

Similarly, another respondent argued:

If anything is provided from above, it will not be adopted by the people. [...] [O]nly if a person is born in a free environment [...] he can become a true citizen. [...] All these chambers and committees [...] are only instruments for letting off steam. ${ }^{47}$

These citations expose the conviction - in a small sample of "critical" respondents - that an undemocratic environment obstructs the flourishing of civil society. The lack of involvement of civil society in establishing and defining the rules of engagement of consultative councils - whose members include NTCA representatives - was seen a resulting in a top-down process that reconfirmed civil society's "passivity." This perspective gives credence to

\footnotetext{
${ }^{39}$ Ibid.

${ }^{40}$ As was envisaged by the original NCTA model (Renner 2005).

${ }^{41}$ Although others - due to more extensive experience or networks - noted that they had provided comments on draft policy documents to the authorities, which, they said, had been taken into account. Yet these documents tend to be highly declarative (see below, Effective Participation or Non-Participation?).

${ }^{42}$ Interview with the director of a federal NCA, Moscow, 27 May 2016.

43 The respondent's expression.

${ }^{44}$ Institutions established to facilitate consultation between the state and civil society, at the federal and regional levels. For the federal-level public chamber, see Law "On the Public Chamber of the Russian Federation," No. 32-FZ, 4 April 2005.

${ }^{45}$ Interview with the representative of an NGO providing legal aid to migrants, Moscow, 30 May 2016.

46 Ibid.

${ }^{47}$ Interview with the representatives of an association uniting people from the Caucasus, 30 May 2016.
} 
accounts of "marionette" organizations in Russia, or organizations that are "created by state of governmental officials and have no leadership or constituency in society"; they are seen as being "official constructs" whose representatives "participate in consultations with political leaders as putative representatives of civil society" (Cook and Vinogradova 2006, 34-35; see also Crotty, Hall, and Ljubownikow 2014). Yet a partial convergence of state and civil society activities is not necessarily (or exclusively) the result of top-down management of civil society. Similarly, the said "passivity" might not stem from consciously opting for subservience vis-à-vis state authorities, but from a form of inertia that might have been internalized - possibly as a Soviet legacy, as suggested by one of the respondents cited above. With reference to the sphere of inter-ethnic relations, minority organizations largely reproduce the Soviet practice of channeling the expression of minority identity into cultural activities, often in the form of ethnic festivals. The reproduction of narratives and behaviors stemming from Soviet legacies by both state and non-state actors is in line with the interpretative framework that sees a political culture being shared by the two (Ziegler 2010). NTCA institutions might have remained trapped in a restrictive framework without challenging it due to the difficulty, for many, to "imagine" a different scenario. The fact that civil society organizations and state organs share the same social space and cognitive frames results in particular (dominant) interpretations of social reality being treated as "evident" (on this, see Bourdieu $(1989,18)$ ). In a similar fashion, Osipov argues that Russian NCA can be seen as "an instrument for the exercise of power" (Osipov 2010, 55; 2012, 438): the acceptance of existing practices occurs without direct coercion, being based on a convergence of perceptions and agendas that unifies various societal strata (Osipov 2012, 438).

Rather than challenging an authoritarian state, civil society can then effectively legitimize it, by reproducing analogous discourses (Lewis 2013, 327-28), "patron-client tendencies" and "vertical ties" (Jamal 2007, 20). ${ }^{48}$ And, as a result of the acceptance of the socio-political status quo, minority representatives can be humble about their expectations, as another (critical) respondent suggested:

The former head of [organization X] once mentioned that: "It is good that we have been recognized as a separate ethnic group so far, and we are allowed to preserve our culture and ethnicity."

I think this is because this person does not think about herself as a Russian citizen, having same rights as everybody else living in Russia. [...] this kind of statement might serve as an indicator that something is wrong in Russia [....$^{49}$

A range of respondents expressed an appreciation for the Russian state's recognition of their ethnic identity. They observed that their experience as national minorities in Russia was positive because they could celebrate (and show to others) their culture, at festivals and other events. Ethnic festivals were valued despite the narrow scope of cultural expression they envisaged. ${ }^{50}$ Certainly the respect with which many NTCA respondents referred to the

\footnotetext{
48 Jamal was writing about the Palestinian state.

${ }^{49}$ Interview with the leader of a regional NCA, Petrozavodsk, 25 April 2016.

${ }^{50}$ Festivals follow the format of folkloristic events, with performances by a range of ethnic groups.
} 
Russian government may have derived from fear of the potential consequences of criticism. At the same time, other interpretations are possible: the last cited respondent suggested that minority representatives" "humility" could be linked to perceptions of an "inferior" status for not belonging to the ethnic majority. Indeed, a widespread attitude among respondents was that Russia's minorities could not simply "claim" (pretendovat') resources or initiatives from the state. There were rarely references to the Russian state's positive obligations to promote minority cultures, as foreseen by international treaties in the sphere of minority rights to which Russia had acceded. ${ }^{51}$ In the majority of cases, responsibility was redirected to individual minority representatives, who themselves were to preserve their cultures and languages by practicing them and passing them on to younger generations. In most cases respondents did not refer to international minority rights law, while public officials have tended to consider international standards as having only limited relevance to Russia (Prina 2016). ${ }^{52}$ This created an endogenous political culture (and insularity from international norms) which constituted an additional commonality of NTCA institutions and the state.

\section{Us or Them? Blurred Boundaries and Restricted Autonomy}

These commonalities are reinforced by the blurred boundaries between state and non-state structures, in the sphere of inter-ethnic relations and more generally. In consultative councils and committees on inter-ethnic relations, members comprise public officials, ${ }^{53}$ giving rise to "hybrid" institutions, positioned "in between" state and non-state actors (those that one respondent - cited above ${ }^{54}$ - had defined as "state/civic institutions"). This fuzziness can advance the absorption of civil society into the political system.

An extra layer of complexity exists in the ethnic republics. Some respondents were - or had been at different stages - involved in both NTCA institutions and government structures. This emerged, in particular, in interviews in Mordovia: as one respondent put it, the Mordovian people's congress unites representatives of Mordovian nationality (narod); at the same time, public officials in charge of nationalities policy in Mordovia also belong to the same narod when they are of Mordovian descent ${ }^{55}$ (a condition perhaps inevitable: in the ethnic republics public officials responsible for inter-ethnic relations often belonged to the titular group). Similarly, in Bashkortostan and Tatarstan some respondents were involved in both state structures (including as MPs in the republics' legislatures) and NTCA institutions. Even when respondents had not taken up a double function, the partial convergence of NTCA and state institutions meant that some might have commented positively on state programmes as a reflection of their own (NTCA) activities, while simultaneously consolidating a perception of NTCA and state institutions cooperating towards shared purposes.

\footnotetext{
51 In particular, the Council of Europe's Framework Convention for the Protection of National Minorities, ratified by Russia in 1998 .

52 Despite the Russian government having, as noted, acceded to the international human rights system.

53 Moreover, some social movements are directly created (and managed) by the state as "ersatz social movements" (Robertson 2009: 545).

${ }^{54}$ Interview with the director of a federal NCA, Moscow, 27 May 2016.

${ }^{55}$ Interview with a member of the Inter-Regional Public Organization of Mordovian (Moksha and Erzya)

Peoples, Saransk, 15 June 2015.
} 
In these cases, state and civil society actors see themselves on a continuum. They do not only share the same political culture, itself stemming from common historical, social and political contexts (Ziegler 2010), but also the same networks. They are immersed in "a complex and multi-layered network of materials transactions, personal connections, and organizational linkages" (Lewis 2013, 326; see also Cheskin and March 2015; White 2015, 318); this is particularly significant in Russia, given the preeminent role played by informal practices (Ledeneva 2013) - or "patronal politics," as Hale (2014) calls them - in social and political processes. Many respondents indicated that state-civil society cooperation is to be preferred to contestation. ${ }^{56}$ These attitudes mirror functionalist aspects of the interaction, with civil society complementing the state by carrying out social functions, ${ }^{57}$ including assistance with migrants' integration. ${ }^{58}$ This complementarity is locked into the NCA Law, and particularly 2014 amendments introducing NCA functions that are desirable to the state as they contribute to social stability, including "the harmonization of inter-ethnic relations" and "the social and cultural adaptation and integration of migrants." ${ }^{99}$

In this context, ethnic leaders' relations with public officials become more crucial than those with members of the minority communities that they purportedly represent. And, while elections generally take place within these bodies, as well as internal decision-making during events, their members tend to be drawn from the minority's elite. ${ }^{60}$ This can result in a lack of horizontal links between NTCA institutions and their constituents, ${ }^{61}$ and ease the absorption of minority leaders into a unified political elite. These processes are, in turn, facilitated by Russia's neopatrimonialism, by which the politico-economic order serves the interests of the ruling group (Gel'man 2016), including in the sphere of inter-ethnic relations (Osipov 2015b). Elite-level networks can create a scenario which alleviate personal but not group exclusion (McGarry and Agarin 2014, 1977).

\section{Effective Participation or Non-Participation?}

Respondents displayed different perceptions of what amounted to "participation," "dialogue" "influence" and "effectiveness." In some cases, they considered the activities of NTCA institutions important, but judged them insufficiently effective: for example, one respondent (a Tatar in Bashkortostan involved in NTCA institutions), on the one hand commended the activity of World Congress of Tatars in preserving a cultural link with Tatarstan for Bashkortostan's Tatars; on the other hand, he believed that exclusively cultural activities were not sufficient to reverse the erosion of Tatar language use and impoverishment of the Tatar cultural landscape in the republic. Yet, in most cases, respondents interpreted

\footnotetext{
${ }^{56}$ Ziegler (2010) analyzes these attitudes in relation to Kazakhstan.

${ }^{57}$ See Bindman (2015) on Russia, and Spires (2011) on the same phenomenon in China.

${ }^{58}$ By providing legal aid and Russian-language classes.

${ }^{59}$ Added to Article 1 through Federal Law "On Introducing Amendments to Articles 1 and 4 of the Federal Law 'On National Cultural Autonomy'," No. 336-FZ, 4 November 2014. The same wording was added to Article 4 of the NCA Law, on the activities in which NCAs may engage.

${ }^{60}$ Interviews in Saransk, Petrozavodsk, Kazan, Ufa, Moscow and St Petersburg, 2015-2016.

${ }^{61}$ For example, one observer argued that NTCA representatives did not maintain regular contacts with other members of the community (outside the elite); another observed that leaders of minorities whose representatives included migrant workers tended to distance themselves from their more socially marginalized co-ethnics. Interviews with academics specializing in inter-ethnic relations, in Kazan, 24 June 2015, and in Moscow, 21 October 2015.
} 
"influence" and "effectiveness" of NTCA institutions as being active, in the sense of engaging in sustained cycles of events and activities without these necessarily leading to long-lasting, tangible outcomes.

Meanwhile, NTCA respondents who referred to the existence of a dialogue with the authorities did not tend to elaborate on the details of such dialogue or its impact. ${ }^{62}$ They spoke about discussions that were, in their opinion, open and helpful, ${ }^{63}$ without additional information, while data from government sources (official websites of state institutions responsible for inter-ethnic relations) are scarce. Thus, data are insufficient to assess how, or to what extent, civil society's cooperation with the government may feed into policy-making and implementation. In general, there is little if any evidence of this type of impact (ACFC 2006: §14, 88-95).

The evaluation of effectiveness in the exercise of minorities' participatory rights is complicated by the absence ofa clear definition of NTCA institutions and their functions, which are replaced by general narratives on "cultural development" of nationalities. Such vagueness likely complicates the anchoring of debates, while the difficulty of ascertaining progression towards "cultural development" can advance an acceptance of illusory forms of participation. For example, festivals can give an impression of "participation," in the sense of active involvement in events, even though NTCA institutions may display the (already mentioned) "passivity" by following pre-existing rituals. Most respondents considered festivals' rituals of folkloristic performances as highly meaningful to the life of the community: engagement with these events has tended to create feelings of social inclusion. A minority of respondents, however, saw festivals and cultural production - while not unimportant - as having only a minute impact on the life of the community and longer-term cultural preservation; they could be regarded as forms of "non-participation" camouflaged as "participation." Conversely, involvement in these events contributes to legitimizing existing narratives of inter-ethnic relations through the symbolism of rituals during holidays and festivals (Adams 2010; Cummings 2010). It consolidates the state's discursive (near)monopoly, reinforced though the media, the practices of state institutions and public events (Lewis 2013, 331-33).

The type of minority "voices" emerging from these dynamics relates to the expression of group consciousness and mutual support between members (Young 2000, 165): NTCA institutions provide a modicum of representation of interests and services to persons that are often starved of resources. At the same time, this limits NTCA institutions to "selforganization," or an "internal voice," rather than "voice" in the sense of "effective participation" (Malloy 2015) that could be projected outside the group and reverberate across society. Yet, in the presence of illusory forms of participation, not all are equally captured by the illusion.

\footnotetext{
62 There were some exceptions, albeit relating to interventions that allowed only minor alternations to the unfolding of government policies: some respondents spoke about input into the wording of official (if declarative) documents on inter-ethnic relations; others pointed to some influence on decision-making at the local level - i.e. on state support for educational or cultural institutions used by their communities.

${ }^{63}$ Again, this positive spin on dialogue might have been exaggerated by the respondents in the interviews.
} 


\section{Alternative Narratives as "Internal Voices"}

Interviews also exposed alternative narratives. In the first instance, we should note that the "acceptance" of existing practices at times occurred with reluctance, given the scarce practical opportunities to implement activities beneficial to minority communities. This is a case that Cheskin and March $(2015,266)$ call "dissentful compliance" ("begrudging compliance that lacks ideological motivation"), as opposed to "consentful compliance." ${ }^{.64}$ For example, a respondent who had averred that her minority's regional NCA was ineffective (and who instead ran her own non-NTCA organization) later revealed that she was a member of the regional NCA's executive council: "We are all in the council. What [else] can we do?"65 At the same time, different attitudes with regard to passivity/loyalty created fractures within some NTCA institutions, weakening horizontal links. ${ }^{66}$

Second, while many respondents placed the state and NTCA institutions on a continuum, a small number distanced themselves from the authorities. In these cases, respondents expressed disapproval of government policies as well as, at times, approval. ${ }^{67}$ Among specific rejections of existing narratives, one respondent disagreed with the view, common among her colleagues (and already reported above), that minority groups should be appreciative of the opportunity to express their cultural distinctiveness through festivals:

Why do I have to be grateful for this? I was born here, I am an active citizen and I think that the state has to help and encourage me in what I am doing, not just allowing or not to sing Ukrainian songs or dance Lithuanian dances. I feel very strongly that $[\ldots]$ the state has to protect minorities. ${ }^{68}$

The varied reactions to dominant narratives point to heterogeneity among representatives of NTCA institutions specifically, and Russian social strata more generally. This finding challenges the view by which large sections of the population - state officials, academics and media professionals and civil society - are seen as sharing the same language, perceptions and priorities in relation to Russia's NTCA system (Osipov 2012: 438) and inter-ethnic relations more generally. While dominant narratives certainly exist, and many appear to have been internalised through invisible mechanisms, alternative views are also present.

Despite the existence of alternative views, the reality is a scarcity of options to turn them into social mobilization. Thus, the status quo is preserved through the pervasiveness of dominant social narratives, and because of the lack of practical means to produce (and disseminate) counter-narratives. Besides the absence of mechanisms and resources, the coercive nature of the Russian state plays a significant role: ${ }^{69}$ despite this, coercive elements in relation to

\footnotetext{
${ }^{64}$ See also Chebankova $(2015,244-45)$ on 'latent dimensions' mobilization.

65 The respondent was of Tatar ethnic background. Interview in Ufa, 23 May 2016.

66 This view was expressed, for example, by representatives of a people's congress and regional NCA, who considered the leaders of their institutions too eager to please the authorities. Interviews with representatives of the Karelian people's congress, Petrozavodsk, 27 April 2016, and the Tatar regional NCA of the Republic of Bashkortostan, Ufa, 23-25 May 2016.

${ }^{67}$ There was also some variation in respondents' experiences with public officials, some of which were seen as more cooperative and well-disposed towards NTCA institutions than others (see also Prina 2016).

${ }^{68}$ Interview with the leader of a regional NCA, Petrozavodsk, 25 April 2016.

${ }^{69}$ See above (The External Environment: Russia's Political Centralism)
} 
Russia's NTCA have been relatively understated in the literature, as scholars searched for reasons for the willing internalization of practices (e.g. Osipov 2010, 2012, 2015a). It is a combination of both external (including coercive) and internal factors that leads to a form of state-NCTA interaction that can only be regulated by an overarching agreement on rules of behaviour.

\section{Conclusion}

This article placed NCTA institutions in the context of (broadly-defined) participation. It looked at attitudes of the majority of respondents from NTCA institutions through the lens of a few critical voices, both insiders and observers (academics or representatives of non-NTCA minority organizations). Interview data point to a generalized consensus (on rules of engagement and objectives) between the state and NTCA institutions. This consensus continues to prevail despite the fact that, while existing rules and opportunities may be used by minority groups, representatives of NTCA institutions are largely precluded from involvement in the actual shaping of such rules, and remain confined to the margins of Russia's political community.

NCTA institutions' peripherality is linked to a combination of external and internal factors. With regard to the former, NCTA institutions have developed in an undemocratic environment, which excluded them from participating in shaping the institutional framework upon which they hinge. This has resulted in an overall weak form of NTCA and noninstitutionalization of mechanisms to advance minority rights, including in the sphere of selfgovernance - as NCTA institutions operate primarily as "regular" NGOs. With reference to internal characteristics, NTCA organizations often display a form of "passivity" in the sense of non-challenge (and internalization) of existing practices. Other internal factors include a partial convergence of NTCA institutions and state organs, and illusory forms of participation.

The said external and internal factors are mutually reinforcing: their interaction consolidates a prevailing consensus, impeding potential challenges to the status quo. While the state gives little, NTCA organizations generally refrain from asking for more, particularly with regard to structural changes that might lead to more effective participation. Consensus can then become a double-edged sword, promoting cooperation between civil society and the state, but also limiting opportunities for substantive civil society's input - creating, instead, a situation whereby the state envelops civil society. .

At the same time, NTCA institutions - like civil society more generally - are multifaceted. Consequently, multiple interpretative frameworks may be employed to shed light on these institutions' actions and their positioning vis-à-vis the state - encompassing political culture, functionalist and discursive approaches. In order to access the NTCA system, and its (albeit limited) benefits, its stakeholders must have at least a degree of acceptance of the social contract behind it. Thus, the non-discursive scenario applies in all cases, as all actors are prevented from introducing alternative discourses into the public domain. The political culture and functionalist framework seem to be true for many (but not all) respondents, who have largely internalized existing practices. 
While the "critical" respondents' voices are enfeebled due to the restrictions placed on their discursive activities, some have rejected the principles underpinning the social contract on which NTCA is based. The fact that some "competing agendas" - and a movement from internal activity to external discursive activity - can at least be imagined by some exposes cracks in the system. It further reveals multiple layers of peripherality along with multiple forms of consensus.

\section{Bibliography}

Advisory Committee on the Framework Convention for the Protection of National Minorities (ACFC 2000), (First) Report submitted by the Russian Federation, 8 March 2000, ACFC/SR(1999)015.

ACFC (2005), (Second) Report submitted by the Russian Federation, 26 April 2005, $\mathrm{ACFC} / \mathrm{SR} / \mathrm{II}(2005) 003$

ACFC (2006), (Second) Opinion on the Russian Federation, 2 May 2007, ACFC/OP/II(2006)004

ACFC (2010), (Third) Report submitted by the Russian Federation, 20 December 2016, ACFC/SR/III(2010)005.

ACFC (2011), (Third) Opinion on the Russian Federation, 24 November 2011, ACFC/OP/III(2011)010.

ACFC (2016), (Forth) Report submitted by the Russian Federation, 9 April 2010, ACFC/SR/IV(2016)006

Adams, Laura L. 2010. The Spectacular State : Culture and National Identity in Uzbekistan. Durham, NC: Duke University Press.

Ambrosio, Thomas. 2009. Authoritarian Backlash: Russian Resistance to Democratization in the Former Soviet Union. Burlington, VT: Ashgate.

Bacon, Edwin, and Bettina Renz. 2006. Securitising Russia: The Domestic Politics of Putin. Manchester; New York: Manchester University Press.

Bauer, Otto. 2000. The Question of Nationalities and Social Democracy. Minneapolis and London: University of Minnesota Press.

Bindman, Eleanor. 2015. "The State, Civil Society and Social Rights in Contemporary Russia, East European Politics." East European Politics 31 (3): 342-60.

Bourdieu, Pierre. 1989. "Social Space and Symbolic Power." Sociological Theory 7 (1): 14-25.

Bowring, Bill. 2005. "Burial and Resurrection: Karl Renner's Controversial Influence on the 'National Question' in Russia." In National-Cultural Autonomy and Its Contemporary Critics, edited by E. Nimni, 191-206. London: Routledge.

Bowring, Bill. 2007. "The Tatars of the Russian Federation and National-Cultural Autonomy: A Contradiction in Terms?" Ethnopolitics 6 (3): 417-35.

Chebankova, Elena. 2015. "Competing Ideologies of Russia's Civil Society." Europe-Asia Studies 67 (2): 244-68.

Cheskin, Ammon, and Luke March. 2015. "State-Society Relations in Contemporary Russia: New Forms of Political and Social Contention," East European Politics 31 (3): 261-73.

Cohen, Jean L., and Andrew Arato. 1994. Civil Society and Political Theory. Cambridge, MA: MIT Press.

Cook, Linda J., and Elena Vinogradova. 2006. "NGOs and Social Policy-Making in Russia's Regions." Problems of Post-Communism 53 (5): 28-41.

Crotty, Jo, Sarah Marie Hall, and Sergej Ljubownikow. 2014. "Post-Soviet Civil Society Development in the Russian Federation: The Impact of the NGO Law." Europe-Asia Studies 66 (8): 1253-69.

Cummings, Sally N. 2010. Symbolism and Power in Central Asia: Politics of the Spectacular. Abingdon: Routledge. 
Gel'man, Vladimir. 2016. “The Vicious Circle of Post-Soviet Neopatrimonialism in Russia." PostSoviet Affairs 32 (5): 455-73.

Gel'man, Vladimir, and Andrey Starodubtsev. 2016. "Opportunities and Constraints of Authoritarian Modernisation: Russian Policy Reforms in the 2000s." Europe-Asia Studies 68 (1): 97-117.

Gilbert, Leah. 2016. "Crowding Out Civil Society: State Management of Social Organisations in Putin's Russia." Europe-Asia Studies 68 (9): 1553-78.

Hale, Henry E. 2014. Patronal Politics: Eurasian Regime Dynamics in Comparative Perspective. Cambridge: Cambridge University Press.

Hilliker, Kirk. 2012. "Civil Society and State-Centred Struggles." Journal of Contemporary African Studies 30 (1): 35-47.

Hofmann, Rainer. 2006. "Political Participation of Minorities." European Yearbook of Minority Issues 6: $5-17$.

Horvath, Robert. 2011. "Putin's 'Preventive Counter-Revolution': Post-Soviet Authoritarianism and the Spectre of Velvet Revolution." Europe-Asia Studies 63 (1): 1-25.

Jamal, Amaney. 2007. Barriers to Democracy: The Other Side of Social Capital in Palestine and the Arab World. Princeton, NJ: Princeton University Press.

Juviler, Peter, and Sherrill Stroschein. 1999. "Missing Boundaries of Comparison: The Political Community." Political Science Quarterly 114 (3): 435-53.

Korosteleva, Elena. 2012. "Questioning Democracy Promotion: Belarus' Response to the 'Colour Revolutions'.” Democratization 19 (1): 37-59.

Kössler, Karl. 2015. "Conclusions: Beyond the Illusion of Ethno-Culturally Homogenous Territory." In Minority Accommodation through Territorial and Non-Territorial Autonomy, edited by Tove H. Malloy and Francesco Palermo, 245-72. Oxford: Oxford University Press.

Lavinski, Kirill. 2013. "Non-Governmental Organizations in Russia: Legal Aspects." Voprosy Rosiiskogo i Mezhdunarodnogo Prava 1: 10-34.

Ledeneva, Alena. 2013. Can Russia Modernise? Sistema, Power Networks and Informal Governance. Cambridge: Cambridge University Press.

Lewis, David. 2013. "Civil Society and the Authoritarian State: Cooperation, Contestation and Discourse." Journal of Civil Society 9 (3): 325-40.

Ljubownikow, Sergej, Jo Crotty, and Peter W. Rodgers. 2013. "The State and Civil Society in PostSoviet Russia: The Development of a Russian-Style Civil Society." Progress in Development Studies 13 (2): 153-166.

Malloy, Tove H. 2015. "Introduction.” In Managing Diversity through Non-Territorial Autonomy: Assessing Advantages, Deficiencies, and Risks, 1-15. Oxford: Oxford University Press.

Malloy, Tove H., Alexander Osipov, and Balázs Vizi, eds. 2015. Managing Diversity through NonTerritoral Autonomy: Assessing Advantages, Deficiencies and Risks. Oxford: Oxford University Press.

Marko, Joseph. 2006. "Effective Participation of National Minorities: A Comment on Conceptual, Legal and Empirical Problems, 20 October 2006." Strasbourg: Council of Europe.

McGarry, Aidan, and Timofey Agarin. 2014. "Unpacking the Roma Participation Puzzle: Presence, Voice and Influence." Journal of Ethnic and Migration Studies 40 (12): 1972-90.

Nimni, Ephraim. 1999. "Nationalist Multiculturalism in Late Imperial Austria as a Critique of Contemporary Liberalism: The Case of Bauer and Renner." Journal of Political Ideologies 4 (3): 289-314.

Nimni, Ephraim, ed. 2005. Natural Cultural Autonomy and Its Contemporary Critics. London: Routledge.

Nimni, Ephraim. 2007. "National-Cultural Autonomy as an Alternative to Minority Territorial Nationalism." Ethnopolitics 6 (3): 345-64.

Osipov, Alexander. 2004. Natsionalno-Kulturnaya Avtonomiya: Idei, Resheniya, Instituty [National Cultural Autonomy: Ideas, Decisions, Institutions]. St. Petersburg: Centre for Independent Sociological Research.

Osipov, Alexander. 2010. "National Cultural Autonomy in Russia: A Case of Symbolic Law." Review of Central and East European Law 35: 27-57. 
Osipov, Alexander. 2011. "The 'People's Congresses' in Russia: Failure or Success? Authenticity and Efficiency of Minority Representation. Working Paper No. 48.” Flensburg: European Centre for Minority Issues. http://www.ecmi.de/uploads/tx_lfpubdb/Working_Paper_48_Final.pdf.

Osipov, Alexander. 2012. "Implementation Unwanted? Symbolic vs. Instrumental Policies in the Russian Management of Ethnic Diversity." Perspectives on European Politics and Society 13 (4): 425-42.

Osipov, Alexander. 2015a. "Autonomy as Symbolic Production: The Case of Contemporary Russia." In Minority Accommodation through Territorial and Non-Territorial Autonomy, edited by Tove H. Malloy and Francesco Palermo, 179-96. Oxford: Oxford University Press.

Osipov, Alexander. 2015b. "Trans-Ethnic Organizational Settings: Roads to Explanation" 14 (2): 7697.

Prina, Federica. 2016. National Minorities in Putin's Russia: Diversity and Assimilation. Abingdon: Routledge.

Prina, Federica. Forthcoming, 2018. "National in Form, Putinist in Content: Minority Institutions 'Outside Politics'," Europe-Asia Studies.

Renner, Karl. 2005. "State and Nation." In National Cultural Autonomy and Its Contemporary Critics, edited by Ephraim Nimni, 15-47. London: Routledge.

Roach, Stephen C. 2005. Cultural Autonomy, Minority Rights, and Globalization. Burlington, VT: Ashgate.

Robertson, Graeme B. 2009. "Managing Society: Protest, Civil Society, and Regime in Putin's Russia." Slavic Review 68 (3): 528-47.

Shevtsova, Lilia. 2001. "Russia's Hybrid Regime." Journal of Democracy 12 (4): 65-70.

Smith, David J., and Karl Cordell, eds. 2008. Cultural Autonomy in Contemporary Europe. Abingdon: Routledge.

Spires, Anthony J. 2011. "Contingent Symbiosis and Civil Society in an Authoritarian State: Understanding the Survival of China's Grassroots NGOs." American Journal of Sociology 117 (1): 1-45.

Weller, Marc, and Katherine Nobbs, eds. 2010. Political Participation of Minorities A Commentary on International Standards and Practice. Oxford: Oxford University Press.

White, David. 2015. "Political Opposition in Russia: The Challenges of Mobilisation and the Political-Civil Society Nexus." East European Politics 31 (3): 314-25.

Wilson, Andrew. 2005. Virtual Politics: Faking Democracy in the Post-Soviet World. New Haven: Yale University Press.

Young, Iris Marion. 2000. Inclusion and Democracy. Oxford: Oxford University Press.

Ziegler, Charles, E. 2010. "Civil Society, Political Stability, and State Power in Central Asia: Cooperation and Contestation." Democratization 17 (5): 795-825. 